\title{
Nuclei Release Methods Comparison for Fresh Leaves of Rice (Oryza sativa) for Efficient High Throughput Flow Cytometry Ploidy Studies
}

\author{
Isidre Hooghvorst ${ }^{1,2}$, Xavier Serrat $^{1} \&$ Salvador Nogués ${ }^{1}$ \\ ${ }^{1}$ Departament de Biologia Evolutiva, Ecologia i Ciencies Ambientals, Secció de Fisiologia Vegetal, Universitat \\ de Barcelona, 08028 Barcelona, Spain \\ ${ }^{2}$ ROCALBA S.A., c/Barcelona 15 PO BOX 156, 17001 Girona, Spain \\ Correspondence: Isidre Hooghvorst, Departament de Biologia Evolutiva, Ecologia i Ciencies Ambientals, Secció \\ de Fisiologia Vegetal, Universitat de Barcelona, 08028 Barcelona, Spain. Tel: 34-628-757-804. E-mail: \\ isidrevander@gmail.com
}

Received: March 23, 2019

Accepted: April 12, 2019 Online Published: June 19, 2019

doi:10.5539/jps.v8n2p31

URL: https://doi.org/10.5539/jps.v8n2p31

\begin{abstract}
Flow cytometry trituration methods and the efficiency of isolation buffer solutions are compared in this study for extraction of nuclei from fresh leaves of rice. The razor blade sample trituration procedure has been widely used to release nuclei from tissues in many plant species, and combined with different isolation buffers for low throughput analysis. In contrast, the bead beating trituration method has rarely been used for DNA ploidy determination, despite it being proposed as a less tedious alternative procedure to prepare nuclear suspensions. In this study, bead beating was assessed and compared with the traditional chopping procedure. Each trituration method was combined with one of three nuclear isolation buffers (i.e. Hanson's, Otto's and LB01 buffer). Bead beating was applied for the first time using all three of the buffers, resulting in a rapid and effective procedure for ploidy determination in fresh rice leaves. In addition, bead beating saved, while reducing the exposure of the user to harmful substances. The best results were obtained when Hanson's nuclear isolation buffer was combined with the bead beating trituration method.
\end{abstract}

Keywords: flow cytometry, plant breeding, bead beating, chopping, fresh leaves, Oryza sativa, doubled haploid, anther culture

\section{Introduction}

Flow cytometry (FCM) is an analytical technique that allows multiparametric analysis to be performed on any stained particle sized between 0.2 and $150 \mu \mathrm{m}$. The FCM technique was first developed in the 1950s to count blood cells (João et al., 2006b). Currently, FCM is widely applied to perform different types of analysis in diverse areas of investigation (Langerhuus et al., 2012; Trend et al., 2015; Zedek et al., 2016). Nevertheless, it was not until the late 1980s that FCM became an important technique in plant research, nuclear DNA content estimations, cell cycle analysis and ploidy determination. The delay in applying FCM in plant science was due to technical problems in obtaining intact nuclear preparations from tissues with rigid cell walls (João et al., 2006a). Estimating ploidy in intact plant cells was unsuitable due to cell wall auto-fluorescence and disturbances to the fluid stream caused by the irregular shape of plant cells. For these reasons, the first reported successful FCM analysis in plants used hydrolytic enzymes to digest cell walls followed by release of the nuclei from fixed preparations.

Galbraith et al., (1983) devised a trituration method in which a suspension of intact nuclei was easily obtained by chopping a small amount of fresh tissue with a razor blade in a suitable isolation buffer. Since then, nuclear isolation via razor blade trituration of plant tissues has been widely used by many authors (Arumuganathan \& Earle, 1991; De Laat et al., 1987; Doležel et al., 1998; Doležel et al., 1989; J.; Doležel \& Göhde, 1995; Hanson et al., 2005; Loureiro et al., 2006a; Miyabayashi et al., 2007; Uozu et al., 1997). However, when the chopping trituration procedure is used, each sample needs to be prepared individually, thus being both time consuming and low throughput. In contrast, an alternative procedure known as bead beating is faster for plant ploidy determinations using FCM. Hanson et al. (2005) showed how samples could be mechanically ground with beads to expose the nuclei and easily extract them with an isolation buffer. Although bead beating has been used in FCM by some authors (Cousin et al. 2009; Roberts, 2007), razor chopping is still the predominant trituration 
procedure for preparing nuclear suspensions. Nevertheless, Cousin et al. (2009) demonstrated the simplicity and efficiency of measuring 192 plant samples within $6 \mathrm{~h}$ via a bead beating procedure to isolate nuclei for FCM.

Alongside these two nuclear extraction procedures, numerous isolation buffers and staining procedures have also been published for FCM in plants. No less than twenty-five nuclear isolation buffers have been developed, including Galbraith's buffer (Galbraith et al., 1983), Hanson's buffer (Hanson et al., 2005), Arumuganathan and Earle's buffer (Arumuganathan \& Earle, 1991), LB01 (Doležel et al., 1989) Tris- $\mathrm{MgCl}_{2}$ (Pfosser et al., 1995), Marie's buffer (Marie \& Brown, 1993) and Otto's buffers (Otto, 1990) as the most popular ones.

FCM is a necessary step in plant breeding when double haploids are desired (Hooghvorst et al., 2018). In rice (Oryza sativa), some authors have used the chopping procedure at different stages in the life cycle, such as the seed stage (Miyabayashi et al., 2007; Uozu et al., 1997) or with young plantlets (Meister, 2005). However, the bead beating procedure has not been used widely to extract intact nuclei and determine ploidy levels, except in Brassica napus, Allium cepa, Nicotiana tabacum, Petroselinum crispum, Rosa canina and $R$. rugosa (Cousin et al., 2009; Roberts, 2007). Furthermore, only Hanson's buffer has been reported as being used during the bead beating trituration method.

The aim of this study is to determine the simplest and most efficient trituration procedures and isolation buffer combinations for rice (O. sativa) ploidy analysis. We report here a comparison between bead beating and the chopping trituration methods, and the use of three different isolation buffers previously used to estimate the DNA ploidy level of plants using haploid, diploid and triploid anther culture derived lines of rice. It is concluded that the three nuclear isolation buffers can be used with bead beating trituration, but the best results were obtained when Hanson's nuclear isolation buffer was used.

\section{Materials and Methods}

\subsection{Preparation of Nuclear Samples}

About $20 \mathrm{mg}$ of fresh young leaves from 3-4-week-old plantlets regenerated from anther culture were used to carry out the study. Leaf samples were obtained in sterile conditions and weighed on a precision scale. When samples were chopped, leaves were placed on a $100 \times 15 \mathrm{~mm}$ polystyrene Petri dish, containing $1 \mathrm{~mL}$ of the appropriate isolation buffer (Hanson's buffer, Otto's buffers and LB01, see Table 1). Samples were chopped for 2-3 minutes using a sharp double-edged razor blade. When bead beating trituration was used, the leaf samples were compacted into spherical shapes and then added to $2 \mathrm{~mL}$ microcentrifuge tubes (Fisher Scientific, Pennsylvania, USA) each containing a steel bead. To each microcentrifuge tube, $300 \mu \mathrm{L}$ of the nuclear isolation buffer was added. Samples were shaken for 48 seconds at $25 \mathrm{~Hz}$ in a $400 \mathrm{MM}$ TissueLyser (Retsch, Mettmann, Germany). The suspension obtained was homogenized by pipetting up and down several times.

Table 1. Nuclear isolation buffers and their chemical composition. The used staining solutions were also specified for each isolation buffer

\begin{tabular}{|c|c|}
\hline Buffer & Composition \\
\hline $\begin{array}{l}\text { Hanson's } \\
\text { [Hanson et al. 2005] } \\
\text { (Hanson et al. 2005) }\end{array}$ & $\begin{array}{l}\text { Isolation buffer: } 0.1 \mathrm{M} \text { citric acid; } 0.5 \% \text { Triton X-100. } \\
\text { Staining solution buffer: } 11.36 \mathrm{~g} \mathrm{Na} \mathrm{HPO}_{4} ; 12 \mathrm{~mL} \text { PI stock }(1 \mathrm{mg} / \mathrm{mL}) ; 20 \mathrm{~mL} 10 \mathrm{x} \\
\text { stock ( } 100 \mathrm{mM} \text { sodium citrate, } 250 \mathrm{mM} \text { sodium sulfate) in } 200 \mathrm{~mL} \text { of distilled water. }\end{array}$ \\
\hline $\begin{array}{l}\text { LB01 } \\
\text { [Doležel et al. 1989] } \\
\text { (J.; Doležel, Binarova, } \\
\text { and Lucretti 1989) }\end{array}$ & $\begin{array}{l}\text { Isolation buffer: } 15 \mathrm{mM} \text { TRIS; } 2 \mathrm{mM} \mathrm{Na}{ }_{2} \mathrm{EDTA} ; 0.5 \mathrm{mM} \text { spermine } 4 \mathrm{HCl} ; 80 \mathrm{mM} \\
\mathrm{KCl} ; 20 \mathrm{mM} \mathrm{NaCl} ; 15 \mathrm{mM} \beta \text {-mercaptoethanol; } 0.1 \%(\mathrm{v} / \mathrm{v}) \text { Triton X-100; } \mathrm{pH} 7.5 \text {. } \\
\text { Staining solution: } \mathrm{PI}(50 \mu \mathrm{g} / \mathrm{mL}) \text {. }\end{array}$ \\
\hline $\begin{array}{l}\text { Otto's } \\
\text { [Otto 1990] } \\
\text { (Otto 1990) }\end{array}$ & $\begin{array}{l}\text { Isolation buffers: } \\
\text { - Otto I: } 100 \mathrm{mM} \text { citric acid; } 0.5 \% \text { Tween } 20 \text {. } \\
\text { - Otto II: } 400 \mathrm{mM} \mathrm{Na} \mathrm{HPO}_{4} \cdot 12 \mathrm{H}_{2} \mathrm{O} \text {. } \\
\text { Staining solution: } \mathrm{PI}(50 \mu \mathrm{g} / \mathrm{mL})\end{array}$ \\
\hline
\end{tabular}

The homogenates were then filtered through $33 \mu \mathrm{m}$ nylon mesh into round-bottomed polystyrene $12 \times 75 \mathrm{~mm}$ test tubes. When Otto's buffers were used, Otto II isolation buffer was added to the nuclear suspension in the test tube at a 1:4 proportion (buffer: suspension).

After nuclei extraction with any of the isolation buffers, RNase $(50 \mu \mathrm{g} / \mathrm{mL})$ was added to each test tube. Twenty minutes later, PI $\left(50 \mu \mathrm{g} \cdot \mathrm{mL}^{-1}\right)$ was added when using LB01 or Otto's isolation buffer, while the staining solution specific to Hanson's buffer was added in a 1:2 proportion (stain:buffer). Samples were incubated for fifteen minutes on ice and in the dark before analysis, shaking the test tube occasionally. 


\subsection{Flow Cytometry}

Samples were analyzed by using a Gallios ${ }^{\mathrm{TM}}$ flow cytometer (Beckman Coulter, Indianapolis, USA) provided by the Centres Cientifics $i$ Tecnologics of the Universitat de Barcelona (CCiTUB). This cytometer was equipped with a high-throughput sampler and four different lasers: blue solid-state diode $(488 \mathrm{~nm})$, yellow solid-state diode $(561 \mathrm{~nm})$, red solid-state diode $(638 \mathrm{~nm})$ and violet solid-state diode $(405 \mathrm{~nm})$. Nuclear PI fluorescence was measured using the $488 \mathrm{~nm}$ laser.

Samples were run at a low flow rate $\left(10 \mu \mathrm{L} \cdot \mathrm{min}^{-1}\right)$ and this flow was kept constant throughout the experiment. In every sample 5,000 nuclear signals were analyzed during a maximum of 600 seconds. To ensure that all 5,000 of the nuclei were detected in each sample, two delimiting conditions were established. Both delimiting areas were defined by analyzing diploid samples prepared with chopping and bead beating procedures. Only events or particles inside both the FSC (forward-scattered light dispersion, proportional to the area or size) and SSC (side-scattered light dispersion, proportional to the internal complexity) delimiting fluorescence intensity areas, as defined with control samples, were considered nuclei. Sample data were acquired using Summit Software v4.3 (Cytomation, Colorado, USA).

\subsection{Experimental Design and Statistics}

During this study, nine samples were prepared for each experimental condition. Six different methodologies were applied to obtain a suitable nuclear suspension, assessing three different isolation buffers and two different trituration procedures. The three nuclear isolation buffers used were: (i) Hanson's buffer (Hanson et al., 2005), (ii) LB01 buffer (Doležel et al., 1989) and (iii) Otto's buffers (Otto, 1990). Two of these buffers were applied in a one-step protocol (Hanson's and LB01) while the last one (Otto's) was used as a two-step protocol. In the case of Hanson's nuclear isolation buffer, the staining solution used to label nuclei was a buffer described by the same author containing propidium iodide (PI). Because the stain was crucial for assessing ploidy, PI was also selected for the other buffers.

With the aim of making a complete comparison between nuclear extraction procedures and isolation buffers in each procedure, the following parameters were recorded: time (minutes) needed for sample preparation taking into account the time invested in sample collection, development of the relevant protocol and run time of the flow cytometer for ploidy determination; the half peak coefficient of variation (HP-CV (\%)) of the resulting peak, this parameter estimating nuclear integrity and DNA staining variation; debris background factor (DF (\%)) of the nuclear suspension; nuclear yield factor (YF (nuclei $\cdot \mathrm{s}^{-1} \cdot \mathrm{mg}^{-1}$ )) which calculated the amount of nuclei in suspension. Statistical analyses were carried out using Welch's ANOVA with Statgraphics Centurion XVII (Statpoint Technologies, Inc. Warrenton, Virginia, USA). All the data were analyzed at the 95\% confidence level.

\section{Results}

\subsection{Ploidy Determination}

DNA content and plant ploidy were measured in both trituration methods with the three isolation buffers and in the different ploidy plants. Reference peaks from the chopping or bead beating procedures were detected in different channels. Thus, diploid plants showed a reference peak around channel 250 with the chopping procedures, and 280 when using the bead beating procedures. Moreover, in both trituration procedures, the reference peaks of the haploid samples correlated to half the value of their diploid counterparts, with 125 in the chopping procedures and 140 in the bead beating procedures (Fig. 1). Triploid samples were also found around channels 375 and 420 when using the chopping and bead beating procedures, respectively.

The samples prepared using the chopping procedure did not have any type of irregularity in the PI fluorescence reading along the time axis. However, obstructions in the injection needle were observed for bead beating samples. As a consequence, large numbers of particles were injected suddenly through the needle when the obstruction was cleared, resulting in a linear PI intensity dispersion. These obstructions appeared equally in every sample when using bead beating, independent of the isolation buffer used.

\subsection{Trituration Method}

Sample trituration using the chopping procedure was slow and tedious compared to bead beating. The bead beating method was faster than chopping, taking from 8.39 to 11.52 and 26.49 to 32.83 minutes, respectively (Table 2). The step that highly reduced was the automatic trituration procedure in bead beating. The HP-CV parameter showed no significant differences between the sample trituration procedures $(\mathrm{P}>0.05)$. The HP-CV average was $5.10 \%$ for the chopping procedure and $5.08 \%$ for the bead beating procedure.

Significant differences between both trituration procedures were found $(\mathrm{P} \leq 0.05)$ for the DF. The DF was 
significantly higher in samples prepared with bead beating with an average of $47.67 \%$ compared to $33.27 \%$ with chopping (Table 2). Significant differences between trituration procedures $(\mathrm{P} \leq 0.001)$ were also observed in the YF. The average YF observed with the chopping procedure was 0.82 , while the average calculated from bead beating was 3.16 nuclei $\cdot \mathrm{s}^{-1} \cdot \mathrm{mg}^{-1}$.

Table 2. Mean and SD values for half peak coefficient of variation (HP-CV) percentage (\%), time analysis (s), debris background factor (DF) percentage (\%), nuclear yield factor (YF) (nuclei $\cdot \mathrm{s}^{-1} \mathrm{mg}^{-1}$ ) values, and consumed time (min) per sample in relation to the methodology assayed: chopping and bead beating trituration technique combined with three buffers assayed, Hanson, Otto and LB01

\begin{tabular}{|c|c|c|c|c|c|c|c|c|c|c|c|c|c|}
\hline Method & \multicolumn{3}{|c|}{$\begin{array}{c}\mathrm{HP}-\mathrm{CV} \\
(\%)\end{array}$} & \multicolumn{3}{|c|}{$\begin{array}{c}\text { Time for analysis } \\
\text { (s) }\end{array}$} & \multicolumn{3}{|c|}{$\begin{array}{l}\mathrm{DF} \\
(\%)\end{array}$} & \multicolumn{3}{|c|}{$\begin{array}{c}\mathrm{YF} \\
\left(\text { nuclei } \cdot \mathrm{s}^{-1} \mathrm{mg}^{-1}\right)\end{array}$} & Time $(\min )$ \\
\hline \multicolumn{14}{|l|}{ Chopping } \\
\hline Hanson & 4.77 & \pm & 1.05 & 188.51 & \pm & 29.19 & 58.19 & \pm & 25.46 & 1.28 & \pm & 0.48 & 26.49 \\
\hline Otto & 6.33 & \pm & 1.47 & 561.23 & \pm & 102.93 & 15.60 & \pm & 5.02 & 0.30 & \pm & 0.14 & 32.83 \\
\hline LB01 & 3.28 & \pm & 0.70 & 373.51 & \pm & 182.27 & 26.03 & \pm & 5.98 & 0.87 & \pm & 0.50 & 29.01 \\
\hline \multicolumn{14}{|l|}{ Bead Beating } \\
\hline Hanson & 4.05 & \pm & 1.37 & 208.64 & \pm & 116.64 & 42.31 & \pm & 6.04 & 2.65 & \pm & 1.34 & 9.98 \\
\hline Otto & 3.78 & \pm & 1.58 & 308.10 & \pm & 120.08 & 42.17 & \pm & 7.00 & 1.67 & \pm & 0.77 & 11.52 \\
\hline LB01 & 4.69 & \pm & 1.51 & 114.09 & \pm & 48.78 & 58.53 & \pm & 7.47 & 5.16 & \pm & 2.49 & 8.39 \\
\hline \multicolumn{14}{|l|}{ Significance $^{\mathrm{a}}$ in $\mathrm{F}$ tests } \\
\hline Among trituration procedures & & ns & & & $* *$ & & & $*$ & & & $* * *$ & & \\
\hline Among Buffers- Chopping & & $* * *$ & & & $* * *$ & & & $* *$ & & & $* *$ & & \\
\hline Among Buffers-BB & & ns & & & $* *$ & & & $* *$ & & & $*$ & & \\
\hline
\end{tabular}

${ }^{\mathrm{a}} \mathrm{ns}$, not significant $(\mathrm{P}>0.05) ; * \mathrm{P}<0.05 ; * * \mathrm{P}<0.01 ; * * * \mathrm{P}<0.001$

\subsection{Isolation Buffer}

Sample preparation time was similar when using Hanson's and LB01 buffers, but longer when using Otto's buffers due to the Otto I and Otto II components resulting in a two-step protocol. Time per sample was significantly different between buffers (Table 2), with Otto's buffers in particular requiring 2 to 3 -fold more time compared to the other buffers $(\mathrm{P} \leq 0.01)$.

The average HP-CV $(\%)$ was not significantly different $(\mathrm{P}>0.05)$ between buffers when bead beating was applied to triturate samples (Table 2). In contrast, the average HP-CV (\%) showed significant differences between the three buffers $(\mathrm{P} \leq 0.001)$ under the chopping procedure. The HP-CV $(\%)$ value for LB01 buffer was 3.28\%, which was lower than the values observed in Hanson's and Otto's buffers, which were $4.77 \%$ and $6.33 \%$ respectively.

Although both trituration methods showed significant differences between buffers in terms of $\mathrm{DF}(\mathrm{P} \leq 0.05)$, the lowest debris values were obtained when using Otto's buffers in both of trituration methods.

Significant differences were also found between the trituration methods for $\mathrm{YF}$ ( $\mathrm{P} \leq 0.05$, Table 2). Otto's buffers showed the lowest YF average in both trituration methods, being significantly lower than the YF average observed using Hanson's or LB01 isolation buffers.

\section{Discussion}

Flow cytometry has been used to determine ploidy in plant species since development of this analysis technique. Many isolation buffers have been described for many species, and in 2007 bead beating was introduced as a new trituration method (Roberts, 2007). To assess the viability of adapting bead beating to ploidy analysis in rice we have used a selection of isolation buffers and compared the two known trituration methods. Our results highlight the efficiency and efficacy of the bead beating method. This work shows that when using bead beating trituration there is the possibility of using LB01 and Otto's buffers apart from Hanson buffer, which has been previously used. Clearly, LB01 was the best isolation buffer when the chopping procedure was used for nuclear isolation. On the other hand, Hanson's buffer was the most suitable isolation buffer when bead beating was assessed.

It was possible to determine rice ploidy levels from fresh leaf samples following both the bead beating and chopping trituration procedures. The traditional chopping procedure was expected to work satisfactorily in rice because it has been widely used by other authors (Miyabayashi et al., 2007; Uozu et al., 1997). Our results highlight the usefulness of bead beating method in haploid and double haploid plantlet determinations as shown by Cousin et al. (2009). In addition, our results show that bead beating is a suitable method for preparing nuclear 
suspensions from fresh rice leaves not only using Hanson's buffers, but also LB01 and Otto's buffers.

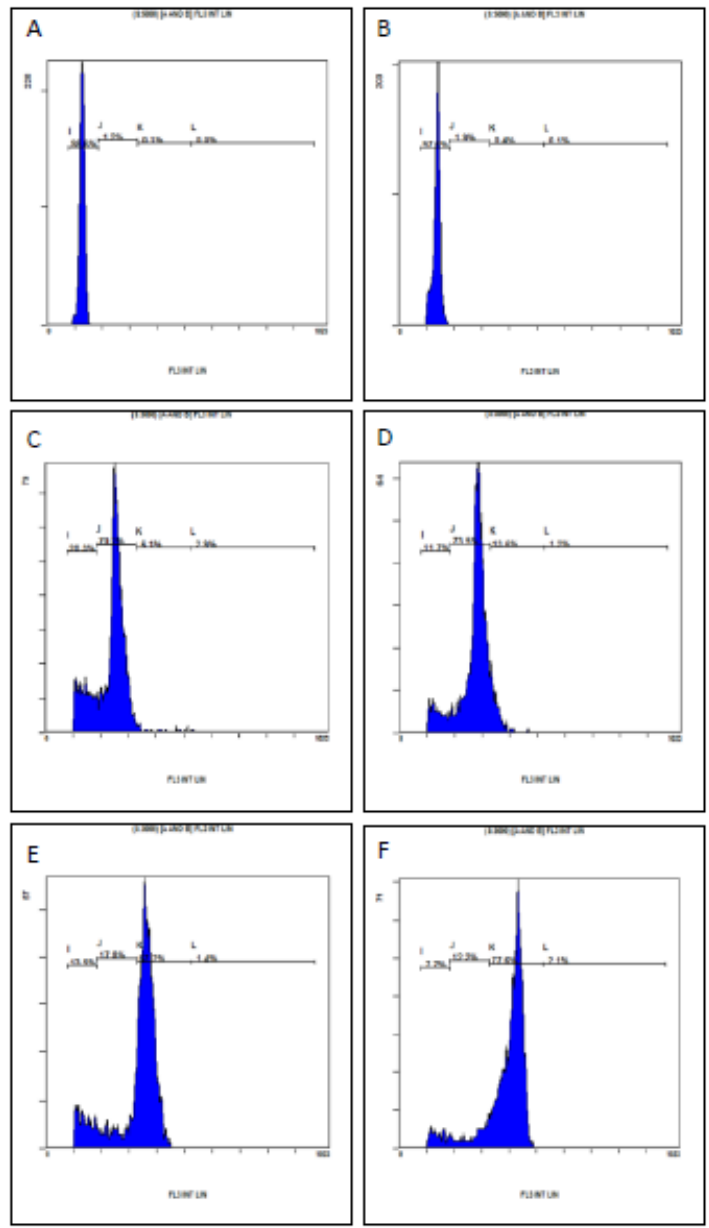

Figure 1. Representative propidium iodide fluorescent histograms corresponding to $G_{0} / G_{1}$ peak of analyzed haploid (A, B), diploid (C, D) and triploid samples using chopping (A, C, E) or beat beating (B, D, F). Peaks were represented from 0 to 1023 channels (X axis) and the number of nuclei corresponding to $G_{0} / G_{1}$ found in each of the channel (Y axis). (A) haploid sample triturated with chopping procedure showed $\mathrm{G}_{0} / \mathrm{G}_{1}$ peak at channel 125. (B) haploid sample triturated with bead beating procedure showed $\mathrm{G}_{0} / \mathrm{G}_{1}$ peak at channel 140 . (C) diploid sample triturated with chopping procedure showed $\mathrm{G}_{0} / \mathrm{G}_{1}$ peak at channel 250. (D) diploid sample triturated with bead beating procedure showed $\mathrm{G}_{0} / \mathrm{G}_{1}$ peak at channel 280. (E) triploid sample triturated with chopping procedure showed $\mathrm{G}_{0} / \mathrm{G}_{1}$ peak at channel 375 . (F) triploid sample triturated with bead beating procedure showed $\mathrm{G}_{0} / \mathrm{G}_{1}$ peak at channel 420

The half peak coefficient of variation (HP-CV) of the DNA peaks was of major importance to determine the quality of the nuclear suspensions (Doležel et al., 1989; Loureiro et al., 2006a; Taylor \& Milthorpe, 1980). DNA peaks with an $\mathrm{HP}-\mathrm{CV} \leq 5.0 \%$ are considered acceptable, while an $\mathrm{HP}-\mathrm{CV} \leq 3.0 \%$ is considered excellent (Galbraith et al., 1983). The HP-CVs were not significantly different $(\mathrm{P}>0.05)$ between the trituration procedures, so the nuclear quality and integrity was unaffected by the trituration method, as pointed by (Roberts, 2007). Bead beating trituration procedures provided average results of around 5.0\%, indicating quite good nuclear integrity, and this was independent of the nuclear isolation buffer used. Roberts (2007) obtained HP-CV values lower than $4 \%$ using bead beating in $R$. rugosa, suggesting that nuclear quality values can be improved depending on the methodology or the species.

The histogram peak positions of haploid, diploid and triploid samples in the cytometer channel ranged the number depending on the trituration method used. Bead beating samples had higher peak channel positions than the chopped samples. This channel displacement could be explained by the fact that the bead beating procedure resulted in rougher nuclear extraction with high amounts of debris present. Consequently, broken or incomplete chloroplasts containing chlorophylls and other subcellular tissue fragments could affect this peak displacement. 
Indeed, the strong red and/or orange auto-fluorescence $(>600 \mathrm{~nm})$ of chlorophylls can cause substantial interference with the PI-based quantitative signal emitted from genetic material, as stated by Hyka et al. (2013). In addition, the same tissue fragments could also have been responsible for the needle obstructions during injection of bead beating samples, contributing to irregular PI fluorescence analyses. Both of the irregularities in the PI fluorescence, which is considered proportional to the amount of genetic material, may have altered the main peak positions of the bead beating samples. Fluorescence interactions from chlorophylls and cytosolic debris have also been reported to affect PI fluorescence by Noirot et al. (2003) and Loureiro et al. (2006a). A correlation between HP-CV and DF was observed by Emshwiller (2002). However, in subsequent studies this correlation was only found in some species, and was not confirmed in many others (Loureiro et al., 2006a). In this study, no correlation was observed between CV and DF and this could be due to the significantly larger amounts of debris found in samples triturated using bead beating, corroborating that chlorophylls and tissue remnants in suspension could affect the fluorescence analyses of bead beating samples and resulting in a channel number displacement. In the same way, the nuclear yield factor values (YF) were significantly higher in bead beating samples than the chopped ones, which indicated greater nuclear extraction and nuclear concentration in these samples. Consequently, bead beating yielded acceptable quality suspensions, obtaining similar HP-CV and higher YF averages than the chopping trituration procedure.

Bead beating minimized the sample preparation costs by reducing the required sample preparation time. Cousin et al. 2009 described a similar procedure using 96-well flow cytometer racks. Furthermore, it is important to consider that when using the traditional chopping procedure, the operator is in a closer contact with isolation buffers and some harmful substances such as $\beta$-mercaptoethanol (Roberts, 2007) than when using bead beating. Thus, the semi-automated bead beating procedure avoids direct contact with toxic reagents.

Nonetheless, the described protocols could be further improved by centrifugation of the nuclear suspension and resuspending the pellet in a smaller volume of isolation buffer. This way, higher YF values could be obtained, although it would increase the sample preparation time and costs. Surprisingly, the main quality parameters obtained from bead beating samples were even better than those observed from chopping samples except for the DF parameter. Although no determining higher number of broken nuclei, it would be advisable to reduce background debris in bead beating samples to obtain even higher quality suspensions in the future.

Years ago, considering the diversity in tissue anatomy and chemistry in plant species, it was thought that no single nuclear isolation buffer would be applicable for nuclear isolation for ploidy determination across all species (Jaroslav et al. 2005). Later quantitative data suggested this was true, and that none of the most popular nuclear isolation buffers worked well with different species (Loureiro et al., 2006a). Therefore, it was important to test different nuclear isolation buffers so that the FCM technique for ploidy determination in rice could be optimized. Our results demonstrated that the ploidy level may be determined in rice by using any of the three tested nuclear isolation buffers. Our data shows a different response of buffers depending on the trituration procedure selected and the suitability of bead beating to perform high quality rice nuclear extractions in a medium-throughput manner

When using the chopping procedure, the best results in general were obtained with LB01 nuclear isolation buffer. Every sample triturated by chopping and using LB01 buffer attained low HP-CV values (HP-CV $\leq 5.0 \%$ ), resulting in preparations of acceptable quality. In contrast, LB01 presented a higher DF average than Otto's buffers when chopping was used, confirming again no correlation between CV and DF in this case. The YF averages obtained when using LB01 buffer and Hanson's buffer were also higher than those yielded using Otto's buffers. The positive results obtained with LB01 buffer may be related to the presence of certain compounds that might counteract the negative effects of some cytosolic compounds such as phenolic substances in suspension (Loureiro et al., 2006b).

Finally, detergents were components of all of the buffers, although the characteristics were not the same. Tween 20 has been confirmed as a weaker detergent, compared to Triton X-100 (Loureiro et al., 2006b). Triton X-100 was used in LB01 and Hanson's isolation buffers at 0.1 and $0.5 \%(\mathrm{v} / \mathrm{v})$ concentration respectively. However, $0.5 \%$ (v/v) Tween 20 was used in Otto's isolation buffers instead. We consider that $0.1 \%(\mathrm{v} / \mathrm{v})$ Triton X-100 was enough to lyse every pigment extracted and to avoid debris aggregations. Nevertheless, it has been observed that increasing the concentration of detergents such as Triton X-100 and Tween 20 up to $0.5-1 \%(\mathrm{v} / \mathrm{v})$, in isolation buffers ensures the lysis of chloroplasts in suspension and avoids debris aggregations (Jaroslav et al. 2005). Given the importance of obtaining low debris background, the latest designed nuclear isolation buffers such as General Purpose Buffer (GPB) and Woody Plant Buffer (WPB) include Triton X-100 at 0.5 and 1\% (v/v) concentrations respectively (Loureiro et al. 2016), and it would be worthwhile assessing these concentrations could have been assessed. 
Bead beating trituration of rice leaf samples produced the best results using Hanson's nuclear isolation buffer. No significant differences were observed between the three assessed isolation buffers in terms of HP-CV, whereas Hanson's and Otto's buffers had lower DF values than LB01. Consequently, there was no correlation between CV and DF observed with bead beating, which was similar to the buffer assessment with chopping. Further, a good YF average was obtained with bead beating using Hanson's buffer. In addition, important cost and time savings were made for sample trituration using Hanson's nuclear buffer with bead beating and the inclusion of $\beta$-mercaptoethanol was avoided. We found that bead beating proved to be a suitable procedure that allowed good quality nuclear extracts to be obtained from rice. Moreover, sample analysis was faster than using the traditional chopping procedure, while also decreasing the cost per sample. Therefore, it would be advantageous to implement this trituration procedure when analyzing other plant species, with consideration given to possible variations in trituration time and frequency as well as isolation buffer composition to achieve the best results.

\section{Acknowledgements}

The authors thank Mirari Ortega for helping with the cytometry work and are also grateful for financial support from the NEURICE project (H2020-SFS-2015-2). The authors declare that they have no conflict of interest.

\section{References}

Arumuganathan, K., \& Earle, E. D. (1991). Estimation of Nuclear DNA Content of Plants by Flow Cytometry. Plant Molecular Biology Reporter, 9(3), 229-241. https://doi.org/10.1007/BF02672073

Cousin, A., Heel, K., Cowling, W. A., \& Nelson, M. N. (2009). An Efficient High-Throughput Flow Cytometric Method for Estimating DNA Ploidy Level in Plants. Cytometry, 75, 1015-1019. https://doi.org/10.1002/cyto.a.20816

De Laat, A. M. M., Gohde, W., \& Vogelzakg, M. J. D. C. (1987). Determination of Ploidy of Single Plants and Plant Populations by Flow Cytometry. Plant Breeding, 99(4), 303-307. https://doi.org/10.1111/j.1439-0523.1987.tb01186.x

Doležel, J., Binarova, P., \& Lucretti, S. (1989). Analysis of Nuclear DNA Content in Plant Cells by Flow Cytometry. Biologia Plantarum (Praha), 31(2), 113-120. https://doi.org/10.1007/BF02907241

Doležel, J., \& Göhde, W. (1995). Sex Determination in Dioecious Plants Melandrium album and M. rubrum Using High-Resolution Flow Cytometry. Cytometry, 19(2), 103-106. https://doi.org/10.1002/cyto.990190203

Doležel, J., Greilhuber, J., Lucretti, S., Meister, A., Lysak, M. A., Nardi, L., \& Obermayer, R. (1998). Plant Genome Size Estimation by Flow Cytometry: Inter-laboratory Comparison. Annals of Botany, 82, 17-26. https://doi.org/10.1006/anbo.1998.0730

Doležel, J., \& Barto, J. (2005). Plant DNA Flow Cytometry and Estimation of Nuclear Genome Size. Annals of Botany, 95(1), 99-110. https://doi.org/10.1093/aob/mci005

Emshwiller, E. (2002). Ploidy levels among species in the "Oxalis tuberosa Alliance" as inferred by flow cytometry. Annals of Botany, 89(6), 741-753. https://doi.org/10.1093/aob/mcf135

Galbraith, D. W., Harkins, K. R., Maddox, J. M., Ayres, N. M., Sharma, D. P., \& Firoozabady, E. (1983). Rapid Flow Cytometric Analysis of the Cell Cycle in Intact Plant Tissues. Science, 220(4601), 1049-1051. https://doi.org/10.1126/science.220.4601.1049

Hanson, L., Boyd, A., Johnson, M. A. T., \& Bennett, M. D. (2005). First Nuclear DNA C-values for 18 Eudicot Families. Annals of Botany, 96(7), 1315-1320. https://doi.org/10.1093/aob/mci283

Hooghvorst, I., Ramos-Fuentes, E., López-Cristofannini, C., Ortega, M., Vidal, R., Serrat, X., \& Nogués, S. (2018). Antimitotic and hormone effects on green double haploid plant production through anther culture of Mediterranean japonica rice. Plant Cell, Tissue and Organ Culture (PCTOC). https://doi.org/10.1007/s11240-018-1413-x

Hyka, P., Lickova, S., Přibyl, P., Melzoch, K., \& Kovar, K. (2013). Flow cytometry for the development of biotechnological processes with microalgae. Biotechnology Advances, 31(1), 2-16. https://doi.org/10.1016/j.biotechadv.2012.04.007

Langerhuus, S. N., Ingvartsen, K. L., Bennedsgaard, T. W., \& Røntved, C. M. (2012). Gram-typing of mastitis bacteria in milk samples using flow cytometry. Journal of Dairy Science, 96(1), 267-277. https://doi.org/10.3168/jds.2012-5813

Loureiro, J., Rodriguez, E., \& Doležel, J. (2016). Two New Nuclear Isolation Buffers for Plant DNA Flow 
Cytometry: A Test with 37 Species. Annals of Botany, 100(4), 875-888.

https://doi.org/10.1093/annbot/mcml52

Loureiro, J., Rodriguez, E., Doležel, J., \& Santos, C. (2006a). Comparison of Four Nuclear Isolation Buffers for Plant DNA Flow Cytometry. Annals of Botany, 98(3), 679-689. https://doi.org/10.1093/aob/mcl141

Loureiro, J., Rodriguez, E., Doležel, J., \& Santos, C. (2006b). Flow Cytometric and Microscopic Analysis of the Effect of Tannic Acid on Plant Nuclei and Estimation of DNA Content. Annals of Botany, 98(3), 515-527. https://doi.org/10.1093/aob/mcl140

Marie, D., \& Brown, S. C. (1993). A Cytometric Exercise in Plant DNA Histograms, with 2C values for 70 Species. Biology of the Cell, 78, 41-51. https://doi.org/10.1016/0248-4900(93)90113-S

Meister, A. (2005). Calculation of binding length of base-specific DNA dyes by comparison of sequence and flow cytometric data. Application to Oryza sativa and Arabidopsis thaliana, 232, 93-97. https://doi.org/10.1016/j.jtbi.2004.07.022

Miyabayashi, T., Nonomura, K., Morishima, H., \& Kurata, N. (2007). Genome Size of Twenty Wild Species of Oryza Determined by Flow Cytometric and Chromosome Analyses. Breeding Science, 57(1), 73-78. https://doi.org/10.1270/jsbbs.57.73

Noirot, M., Barre, P., Duperray, C., Louarn, J., \& Hamon, S. (2003). Effects of caffeine and chlorogenic acid on propidium iodide accessibility to DNA: Consequences on genome size evaluation in coffee tree. Annals of Botany, 92(2), 259-264. https://doi.org/10.1093/aob/mcg139

Noirot, M., Barre, P., Louarn, J., Duperray, C., \& Hamon, S. (2000). Nucleus-Cytosol Interactions-A Source of Stoichiometric Error in Flow Cytometric Estimation of Nuclear DNA Content in Plants. Annals of Botany, 86(2), 309-316. https://doi.org/10.1006/anbo.2000.1187

Noirot, M., Barre, P., Louarn, J., Duperray, C., \& Hamon, S. (2002). Consequences of stoichiometric error on nuclear DNA content evaluation in Coffea liberica var. dewevrei using DAPI and propidium iodide. Annals of Botany, 89(4), 385-389. https://doi.org/10.1093/aob/mcf056

Otto, F. (1990). DAPI Staining of Fixed Cells for High-Resolution Flow Cytometry of Nuclear DNA. Methods in Cell Biology, 33, 105-110. https://doi.org/10.1016/S0091-679X(08)60516-6.

Pfosser, M., Amon, A., Lelley, T., \& Heberle-Bors, E. (1995). Evaluation of Sensitivity of Flow Cytometry in Detecting Aneuploidy in Wheat Using Disomic and Ditelosomic Wheat-Rye Addition Lines. Cytometry, 21(4), 387-393. https://doi.org/10.1002/cyto.990210412

Roberts, A. V. (2007). The Use of Bead Beating to Prepare Suspensions of Nuclei for Flow Cytometry from Fresh Leaves, Herbarium Leaves, Petals and Pollen. Journal of the International Society for Advancement of Cytometry, 71, 1039-1044. https://doi.org/10.1002/cyto.a.20486

Taylor, I. W., \& Milthorpe, B. K. (1980). An evaluation of DNA fluorochromes, staining techniques, and analysis for flow cytometry. The Journal of Histochemistry and Cytochemistry, 28(11), 1224-1232.

Trend, S., De Jong, E., Lloyd, M. L., Kok, C. H., Richmond, P., Doherty, D. A., ... Currie, A. (2015). Leukocyte populations in human preterm and term breast milk identified by multicolour flow cytometry. PLOS ONE, 10(8), 1-17. https://doi.org/10.1371/journal.pone.0135580

Uozu, S., Ikehashi, H., Ohmido, N., Ohtsubo, H., Ohtsubo, E., \& Fukui, K. (1997). Repetitive sequences: Cause for variation in genome size and chromosome morphology in the genus Oryza. Plant Molecular Biology, 35(6), 791-799. https://doi.org/10.1023/A:1005823124989

Zedek, F., Veselý, P., Horová, L., \& Bureš, P. (2016). Flow cytometry may allow microscope-independent detection of holocentric chromosomes in plants. Scientific Reports, 6(February), 27161. https://doi.org/10.1038/srep27161

\section{Copyrights}

Copyright for this article is retained by the author(s), with first publication rights granted to the journal.

This is an open-access article distributed under the terms and conditions of the Creative Commons Attribution license (http://creativecommons.org/licenses/by/4.0/). 